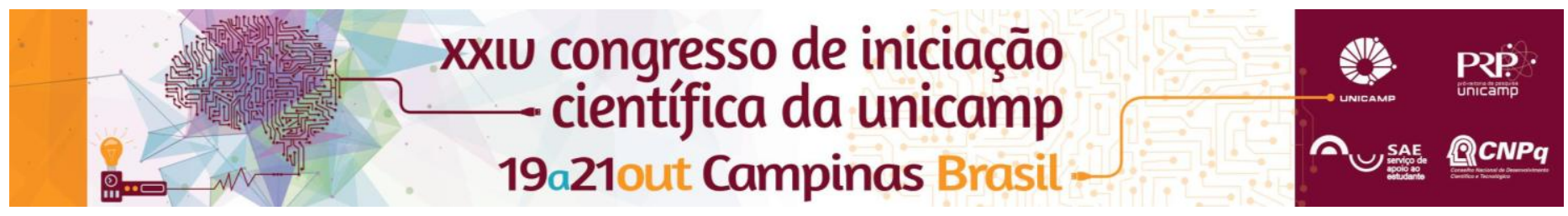

\title{
Influência dos aplicativos de smartphones para transporte urbano no transito
}

\author{
Natália Custódio de Mello*, Maria Teresa Françoso.
}

\begin{abstract}
Resumo
Este projeto tem como objetivo determinar as influências causadas no transito pelo constante desenvolvimento e avanço de aplicativos para smartphones que são capazes de monitorar e criar rotas para o transporte público e privado. Este trabalho iniciou-se com uma vasta pesquisa bibliográfica sobre os tipos e os usos de aplicativos de trânsito baseados em geolocalização. Paralelamente fez-se um estudo detalhado sobre os principais softwares disponíveis no mercado. Em seguida, foram pesquisadas as aplicações desses programas no âmbito dos transportes, bem como as influências causadas pelo uso. Ao final do trabalho elaborou-se um formulário online para determinar a área de influência desses aplicativos e quais são as principais contribuições para o transporte público e privado. Com a pesquisa bibliográfica e a análise das respostas obtidas no formulário pode-se concluir que esses aplicativos causam influencias positivas no trânsito, proporcionando o conhecimento de novas rotas inclusive com trajetos mais eficientes, evitando congestionamentos, entretanto, há alguns pontos que devem ser melhorados como, por exemplo, a apresentação de rotas mais seguras e dados atualizados com regularidade.
\end{abstract}

\section{Palavras-chave:}

Location Based Services, Transporte urbano, Aplicativos.

\section{Introdução}

Com o desenvolvimento tecnológico dos dispositivos móveis (smartphones, tablets), a queda nos preços e a disseminação de redes wireless, $3 G$ e $4 G$, houve um crescimento elevado do mercado de aplicativos móveis (SIQUEIRA, 2012). Unindo os problemas relacionados à mobilidade e o avanço em sistemas cibernéticos cria-se um mercado de aplicativos para smartphones com componentes de posicionamento (FIRE et al., 2012). Ao contrário dos sistemas convencionais de detecção, os aparelhos com Sistema de localização (LBS - Location Based Services) possibilitam aos usuários reproduzir cenários atuais do transporte através da relação entre dados privados de cada aparelho, com a rede pública, mapas e cadastros de rotas.

Com o objetivo determinar as influências causadas no transito pelo constante desenvolvimento e avanço de aplicativos para smartphones foi realizado uma revisão bibliográfica com ênfase nos tipos de aplicativos existentes no Brasil e no mundo separando-os em categorias para automóveis, transporte público, pedestres e bicicletas. Buscando identificar a utilização, influência e preferência de cada aplicativo foi elaborado um formulário para preenchimento online procurando obter o maior número de respostas incluindo pessoas de várias faixa etária, condições financeira e nacionalidades.

\section{Resultados e Discussão}

Como resultado das pesquisas percebeu-se que o uso desses aplicativos está bem consolidado. A grande variedade de funcionalidades e informações disponíveis em cada aplicativo torna-os atraentes tanto para diferentes grupos de usuários, como para modais distintos: transporte público e individual, ou para objetivos diferentes: trajeto mais rápido, rotas mais baratas ou até realizar atividades físicas como corrida e ciclismo.
Verificou-se que a maioria utiliza os: Google Maps e Waze, que são focados para o transporte de automóveis, o que abre a discussão sobre investir mais em aplicativos para diferentes modais de transporte como ônibus, trens, bicicletas entre outros. Pode-se concluir, também, que o usuário não busca apenas obter informações para se chegar a um destino, mas sim uma completa gama de informações como congestionamentos, velocidades médias, radares e perigos nas vias. Observou-se que 99\% dos entrevistados consideram o nível de confiança Alto à Médio nos aplicativos, além de vários relatos de situações onde o uso do software foi satisfatório. Outro aspecto analisado foram as consequências negativas pelo seu uso, como trajeto por vias perigosas, emissão de muitos sinais sonoros, rotas mais longas, falta de atualização das informações das vias e acessos, bem como falhas relacionadas à conexão com a internet.

\section{Conclusões}

Em resumo, pode-se concluir que os aplicativos para transporte urbano causam uma influencia positiva no trânsito reduzindo o tempo de viagem, utilizando rotas mais eficientes e alertando a ocorrência de acidentes. Entretanto, deve-se ressaltar que os mesmos podem causar efeitos negativos como problemas no trajeto devido a falta de atualização de informações ou locais perigosos, distrações pelos alertas e imagens, além de induzir o aumento do fluxo de veículos em ruas locais.

\footnotetext{
Fire, M. et al. Data Mining Opportunities in Geosocial Networks for Improving Road Safety. In: Convention Of Electrical And Electronics Engineers, 27., 2012, Israel. Beer-sheva: IEEE, 2012. p. 1 - 4.

Siqueira, L. G. Aplicação Bus Tracker: Oferecendo uma melhor experiência aos usuários do transporte público, a partir da utilização de informações de rastreamento veicular. 2012. 92
} 